\title{
In day 150 of COVID-19 disease, forecasting the number of cases and
} deaths in Turkey

\author{
Yüksel Akay Ünvan ${ }^{1 *}$, Oguzhan Demirel ${ }^{2}$
}

\begin{abstract}
Objective: This study aims to forecast the number of deaths and cases in Turkey 150 days after (6 August 2020) the first occurrence of COVID-19 in Turkey. The data used is from 10 March 2020 (the first day has seen of COVID-19 in Turkey) to 15 June 2020 and includes people of all ages from all provinces of Turkey.

Material and Method: The relationship between cases, deaths, patients in intensive care units, intubated patients, and recovered patients, which are observations of COVID-19, was examined with a correlation matrix. Afterward, the ARIMA $(0,2,4)$ model to forecast the number of COVID-19 cases in Turkey and the ARIMA $(0,3,1)$ model to forecast the number of COVID-19 deaths in Turkey were established.

Result: COVID-19 cases were forecasted that there may be 266.692 cases in Turkey on 6 August in the 1 st model. Subsequently, a similar forecast has been made on COVID-19 deaths in Turkey on 6 August in the 2nd model. COVID19 deaths were forecasted that there may be 5718. The p-values of these parameters of models were observed statistically significant $(\mathrm{p}<0.05)$. Later, the stationarity of ARIMA models related to these estimates was examined. According to the Augmented Dickey-Fuller (ADF) test results, ARIMA models were stationary and statistically convenient to use $(\mathrm{p}<0.05)$. Finally, the Jarque-Bera $(\mathrm{JB})$ test examining the normal distribution assumption was applied and the models were found to be normally distributed.

Conclusions: Consequently, there is an increase in both predicted cases and predicted deaths by the 150th day of COVID-19. These estimates show that the number of cases and deaths will not decrease to zero level until August 6. Factors such as the biological development of the COVID-19 virus, the rate of spread of COVID-19 disease, or the presence of COVID-19 therapy may not cause any increase in these observations. On the contrary, more than expected increase may occur in observed cases.
\end{abstract}

Keywords: COVID-19, COVID-19 Turkey, SARS-CoV-2, Coronavirus Turkey, COVID-19 forecasting.

\section{Introduction}

Many lethal diseases have emerged throughout the history of mankind. Some diseases lasted for several months and some for years. Nevertheless, mankind has always been the winner of these diseases. Plague disease, which killed 75200 million people between 1331-1353 years; Smallpox disease, which killed 500 million people between 18771977 years and Influenza (Spanish flu) disease, which killed 17-100 million people between 1918-1920 years are some of the hazardous diseases that have been seen recently $(1,2,3)$. The exact number of people who died due to these diseases is unknown, as reports on deaths were not kept clear in the years when the disease happened. Although these outbreaks are shocking to humans, from past to present, technology and medical science are in constant development with these outbreaks. Developing treatment methods have caused mortality rates to decrease.
Diseases and viruses or bacteria that cause them often have different names. Recently, the virus has emerged that affects the entire world and causes many economic, social, and health problems. The virus causing the current epidemic is called severe acute respiratory syndrome coronavirus 2, abbreviated to SARS-CoV-2. The name of the disease caused by this virus has been abbreviated as COVID-19. These names have been given by the World Health Organization (WHO) and the International Committee on Taxonomy of Viruses (ICTV) (4,5). This epidemic was first detected in the city of Wuhan, China. Wuhan is the capital of the Hubei Province and has about 11 million citizens. When the date of 29 December 2019, Chinese experts identified a cluster of similar cases of pneumonia in the city. Thus, the virus that caused these detected cases was called SARS-CoV-2 (6). 
At a later time, the first cases of COVID-19 outside of China were seen on January 13rd in Thailand and on January 16th in Japan. Due to the extraordinary increase in cases, on January 23rd the city of Wuhan and other cities in the zone were placed on lockdown by the Chinese Government. But this lockdown could not prevent the spread of the virus and COVID-19 has spread to many more countries. This spread undoubtedly led to cases in many countries around the world. By March it improved into a global pandemic that was announced by the WHO.

The most important reason for this degree of spread of COVID-19 disease is the rate at which the virus spreads. This virus, which is spread by breathing, can also be found on surfaces, especially in closed environments. Therefore, the use of N95 masks and frequent washing of the hands with soap is plenty significant. According to research in China; each person infected at an average age spreads this disease to an additional two (2.2) people. It was concluded from this research that it is likely that the outbreak will continue to spread until this number falls below 1.0 (7).

Reported illnesses from people have ranged from slight symptoms to severe illness and death for approved Coronavirus disease 2019 (COVID-19) cases. These symptoms such as fever, cough, and shortness of breath might appear in 2-14 days after exposure (based on the incubation period of MERS-CoV viruses). If you realize urgent circumstances for COVID-19, you should get medical attention instantly. Urgent circumstances include these:

\section{-Trouble breathing,}

-Persistent pain or pressure in the chest,

-New confusion or inability to arouse,

-Bluish lips or face.

But other than those on this list, many circumstances can occur, therefore, a healthcare professional should be consulted for other happening symptoms (8). Testing on someone who shows off symptoms of COVID-19 may not always produce accurate results. Success in tests is not yet $100 \%$ due to the new onset of the disease. There are a few reasons why someone infected with COVID-19 might yield a false-negative result when tested $(9,10)$. (i) Infected people may be in the early stage of the disease with a viral load that is too nominal to be unearthed. (ii) Infected people may own no substantial respiratory symptoms, so there could be few detectable viruses in the patient's throat and nose. (iii) There may have been trouble with sample collection, namely, there is a very little sample to test. (iv) There may have been inattentive shipping and poor handling of samples and test materials. (v) There may have been technical issues connatural in the test, e.g. virus mutation.

There is no certain antiviral treatment committed for COVID-19, and no vaccine is currently available. The treatment is symptomatic, and oxygen therapy is the primary treatment method for patients with severe infection. Mechanical ventilation may be necessary in cases of respiratory shortness refractory to oxygen therapy, whereas hemodynamic support is necessary for managing septic shock (11). Although this is not all exact treatment for the disease, many curing methods are being developed every day; for instance, diverse treatment methods have been developed in China, the country of origin of the disease during this process. In early times Vitro studies, chloroquine was found to block COVID-19 infection at low-micromolar concentration, with a half-maximal effective concentration (EC50) of 1.13 micrometer $(\mu \mathrm{M})$ and a half-cytotoxic concentration (CC50) greater than 100 $\mu \mathrm{M}$ (12). These studies in China revealed that it also has potential broad-spectrum antiviral activities by rising endosomal $\mathrm{pH}$ entailed for virus/cell fusion, as well as interfering with the glycosylation of cellular receptors of SARS-CoV $(13,14)$. Therefore, the anti-viral and antiinflammatory activities of chloroquine may explain for its potent efficacy in treating patients with COVID-19 pneumonia. This treatment is recommended for inclusion in the after version of the Guidelines for the Prevention, Diagnosis, and Treatment of Pneumonia caused by COVID-19 issued by the National Health Commission of the People's Republic of China (15). Besides, psychological treatment is also important in this process. Therapies will undoubtedly have an important place in people's defeat of COVID-19. Among these are the RNA polymerase inhibitor remdesivir, chloroquine, the antiviral medication lopinavir-ritonavir, interferon-1 $\beta$, and a variety of traditional Chinese medicine yields (16).

\section{COVID-19 in World Countries}

COVID-19 has been seen in all countries in the world, except for a few countries where data cannot be obtained. Although the origin and spread of the disease first started in China, Europe and South America have become the center of the disease, especially in the latest month. Whilst in the last days, a very serious case increase has been observed especially in Russia, Brazil, Peru, India, Chile, Mexico, and the New York region of the United States of America (U.S.A.). As of 15 June 2020, the distribution of cases in countries where COVID-19 cases were detected is shown in Figure 1 (17). According to Figure 1 given, especially Russia, Brazil, and the U.S.A. are the countries where the cases are seen the most.

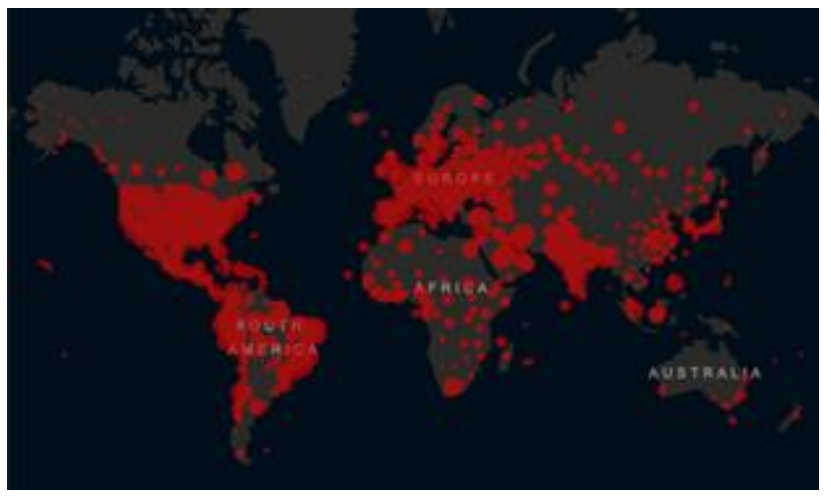

Figure 1: Total Confirmed Cases of COVID-19 (As of June 15, 2020) (17). 


\section{World and Top 10 Countries in COVID-19}

Until 15 June 2020 (198 days), 8046465 people were infected in COVID-19 disease. 437295 of the cases died due to COVID-19. According to these data; the mortality rate of the disease is $5.42 \%$. Though only $0.104 \%$ of the world's population own COVID-19, the high mortality rate is worrying. The top 10 countries in the case list shown are given in Table 1. These countries are the U.S.A., Brazil, Russia, India, The United Kingdom (U.K.), Spain, Italy, Peru, Iran, and Germany. The country with the highest number of cases is the U.S.A. with 2174324 patients. Together with 118121 deaths, the U.S.A. is the country with the utmost number of deaths. Germany, where 172600 cases are recovered $(\% 91,82)$, is the only country that has managed to treat almost all patients. Whenever the cases were compared, Italy has the utmost mortality rate with $14.48 \%$

\section{COVID-19 in Turkey}

According to data released by the Republic of Turkey Ministry of Health, Turkey is one of the most recent countries where COVID-19 has been seen. Although Turkey is 11 th in the number of COVID-19 cases as of 15 June 2020 are in order, it ranks 17 th in terms of population. And 179831 cases were detected in 97 days. Of these, 4825 died, 152364 recovered, 722 were taken to intensive care units (ICU) and 291 are treated as intubated patients.
As of June 15, "Deaths"/"Cases" rate is $2.68 \%$, "Patients in ICU"/"Cases" rate is $0.40 \%$, "Intubated Patients"/"Cases" rate is $0.16 \%$ and "Recovered Patients"/"Cases" rate is calculated as $84.73 \%$.

This recovered rate is well above the world average. COVID-19 has been seen in all the provinces of Turkey and the most widespread cities are İstanbul, Ankara, İzmir, Konya, and Kocaeli. All of these provinces are big cities with a population of more than 1 million. Besides that, the total number of COVID-19 tests conducted until June 15 is 2674203. This cumulative increase in the number of tests is shown in Figure 2 (19). Conforming to these numbers announced, $6.72 \%$ of the tests performed were positive.

When Figure 3 is examined, the number of cases and recovered patients display a steady increase (19). Also, the number of patients recovering from the disease increased on 21 April 2020 with a leap. As the reasons for this leap; the necessity of a certain period of time to treat the disease completely and the positive treatment methods developed can be shown. As of June 15, the growth rates in the variables related to COVID-19 are given in Figure 4 (19). Just as the number of cases was first seen, the cases' growth rates increased quite high initially. The average value of cases growth rates was $18.35 \%$. In the later days of the disease, it was observed that the growth rates of other variables started. The average of other growth rates found are as follows: deaths $12.66 \%$, patients in ICU $4.64 \%$, intubated patients $3.38 \%$, and recovered patients $10.36 \%$.

Table 1: Top 10 Countries in COVID-19 $(17,18)$.

$\begin{array}{lcccccc} & \begin{array}{c}\text { Confirmed } \\ \text { Cases }\end{array} & \text { Deaths } & \begin{array}{c}\text { Recovered } \\ \text { People }\end{array} & \text { Active Cases } & \begin{array}{c}\text { Mortality Rate } \\ \text { (per 100) }\end{array} & \begin{array}{c}\text { Day since the first } \\ \text { case }\end{array} \\ \text { WORLD } & 8,066,465 & 437,295 & 4,174,782 & 3,454,388 & 5.42 \% & 198 \text { days } \\ \text { The } & 2.174 .327 & 118.121 & 875.189 & 1.181 .017 & 5.43 \% & 154 \text { davs } \\ \text { Brazil } & 873,963 & 43,485 & 453,568 & 376,910 & 4.98 \% & 111 \text { days } \\ \text { Russia } & 537,210 & 7,091 & 284,539 & 245,580 & 1.32 \% & 137 \text { days } \\ \text { India } & 342,841 & 9,914 & 180,225 & 152,702 & 2.89 \% & 136 \text { days } \\ \text { The U.K. } & 296,857 & 41,736 & 1,284 & 253,837 & 14.06 \% & 137 \text { days } \\ \text { Spain } & 291,189 & 27,136 & 150,376 & 113,677 & 9.32 \% & 137 \text { days } \\ \text { Italy } & 237,290 & 34,371 & 177,010 & 25,909 & 14.48 \% & 137 \text { days } \\ \text { Peru } & 229,736 & 6,688 & 115,579 & 107,469 & 2.91 \% & 102 \text { days } \\ \text { Iran } & 189,876 & 8,950 & 150,590 & 30,336 & 4.71 \% & 118 \text { days } \\ \text { Germany } & 187,967 & 8,877 & 172,600 & 6,490 & 4.72 \% & 118 \text { days }\end{array}$

Table 2: The Rates of Top 10 Countries in COVID-19 (As of June 15, 2020) (18)

\begin{tabular}{lcccc}
\hline & Population & $\begin{array}{c}\text { Confirmed Cases / } \\
\text { Population (per 100) }\end{array}$ & $\begin{array}{c}\text { Deaths / Population } \\
\text { (per 100) }\end{array}$ & $\begin{array}{c}\text { Recovered People / } \\
\text { Confirmed Cases (per 100) }\end{array}$ \\
WORLD & $7,791,581,688$ & $0.104 \%$ & $0.006 \%$ & $51.75 \%$ \\
The U.S.A. & $330,917,584$ & $0.657 \%$ & $0.036 \%$ & $40.251 \%$ \\
Brazil & $212,492,226$ & $0.411 \%$ & $0.020 \%$ & $51.898 \%$ \\
Russia & $145,931,893$ & $0.368 \%$ & $0.005 \%$ & $52.966 \%$ \\
India & $1,379,381,861$ & $0.025 \%$ & $0.001 \%$ & $52.568 \%$ \\
The U.K. & $67,870,494$ & $0.437 \%$ & $0.061 \%$ & $0.433 \%$ \\
Spain & $46,754,035$ & $0.623 \%$ & $0.058 \%$ & $51.642 \%$ \\
Italy & $60,465,391$ & $0.392 \%$ & $0.057 \%$ & $74.596 \%$ \\
Peru & $32,949,791$ & $0.697 \%$ & $0.020 \%$ & $50.309 \%$ \\
Iran & $83,941,948$ & $0.226 \%$ & $0.011 \%$ & $79.310 \%$ \\
Germany & $83,772,567$ & $0.224 \%$ & $0.011 \%$ & $91.825 \%$ \\
\hline
\end{tabular}




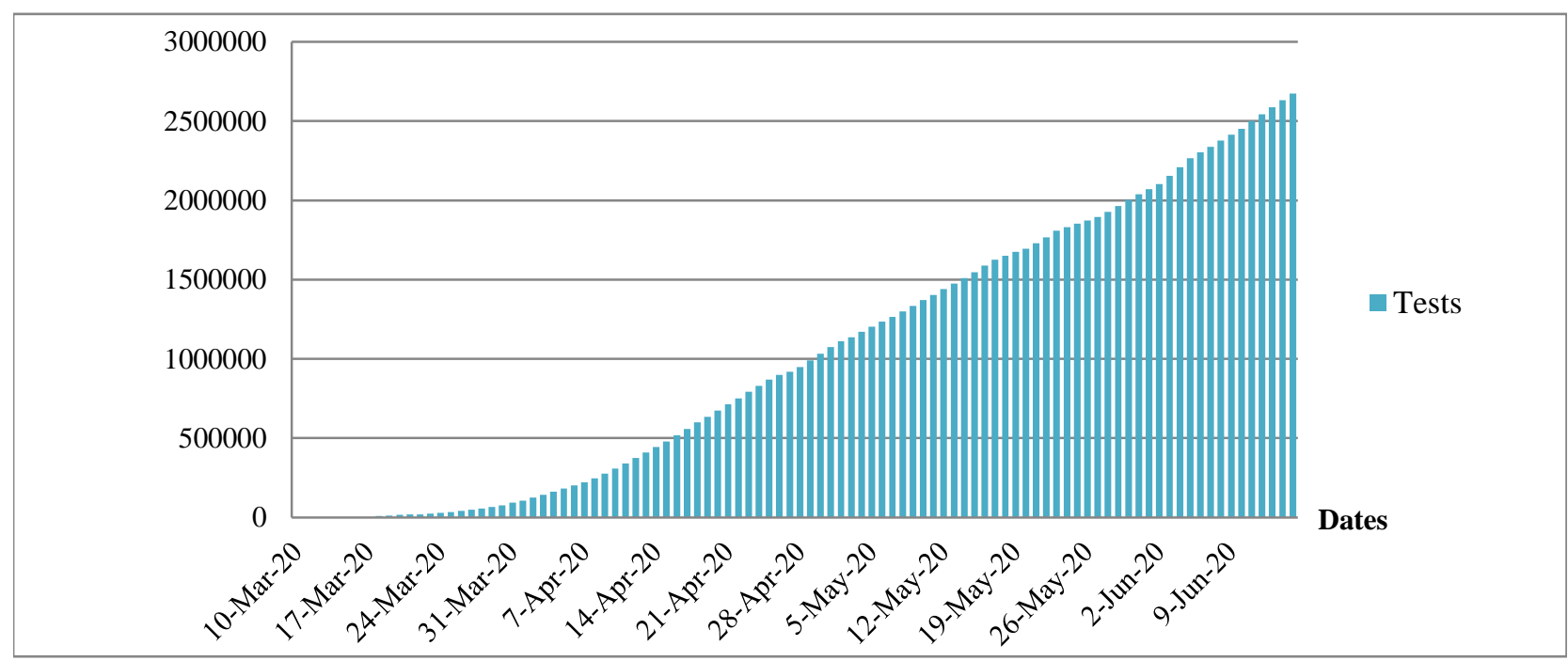

Figure 2: COVID-19 Tests in Turkey (19).

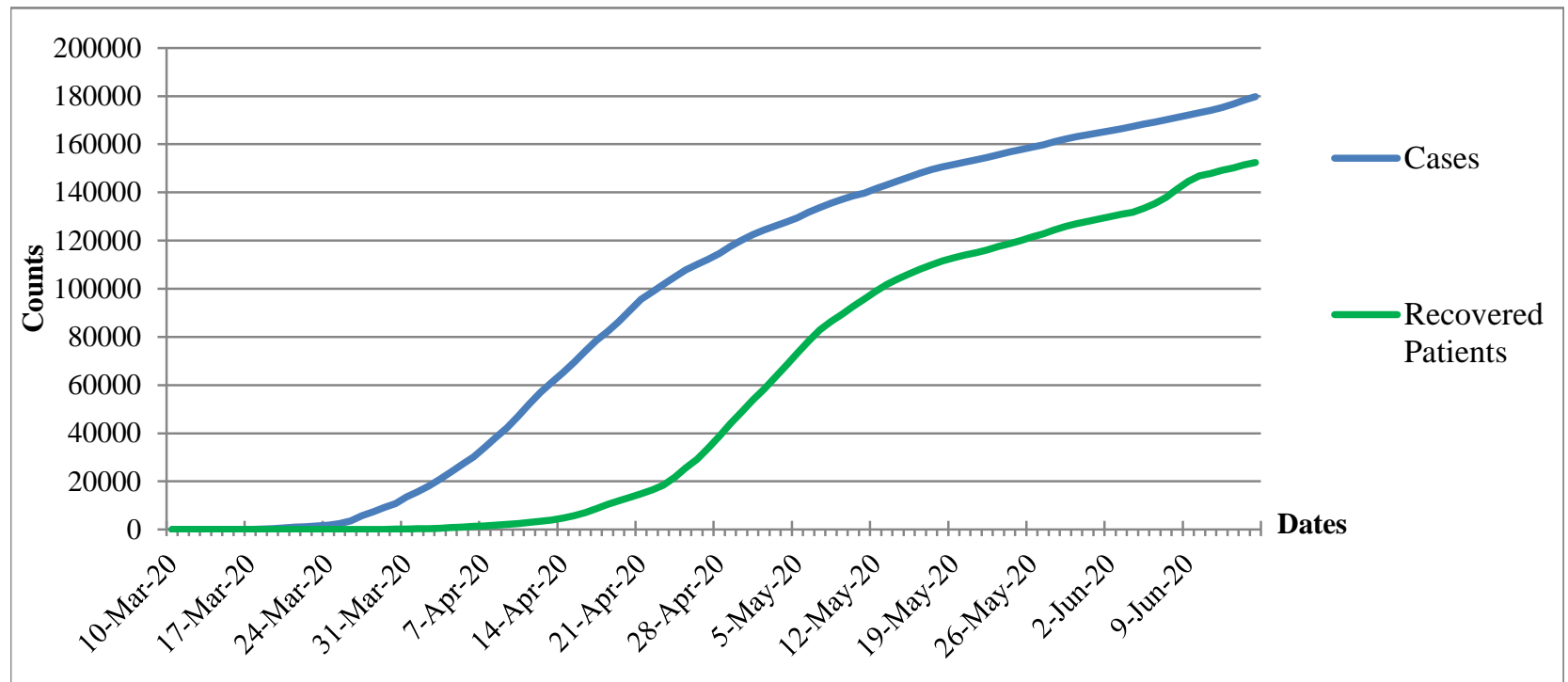

Figure 3: Cases and Recovered Patients Due to COVID-19 (19).

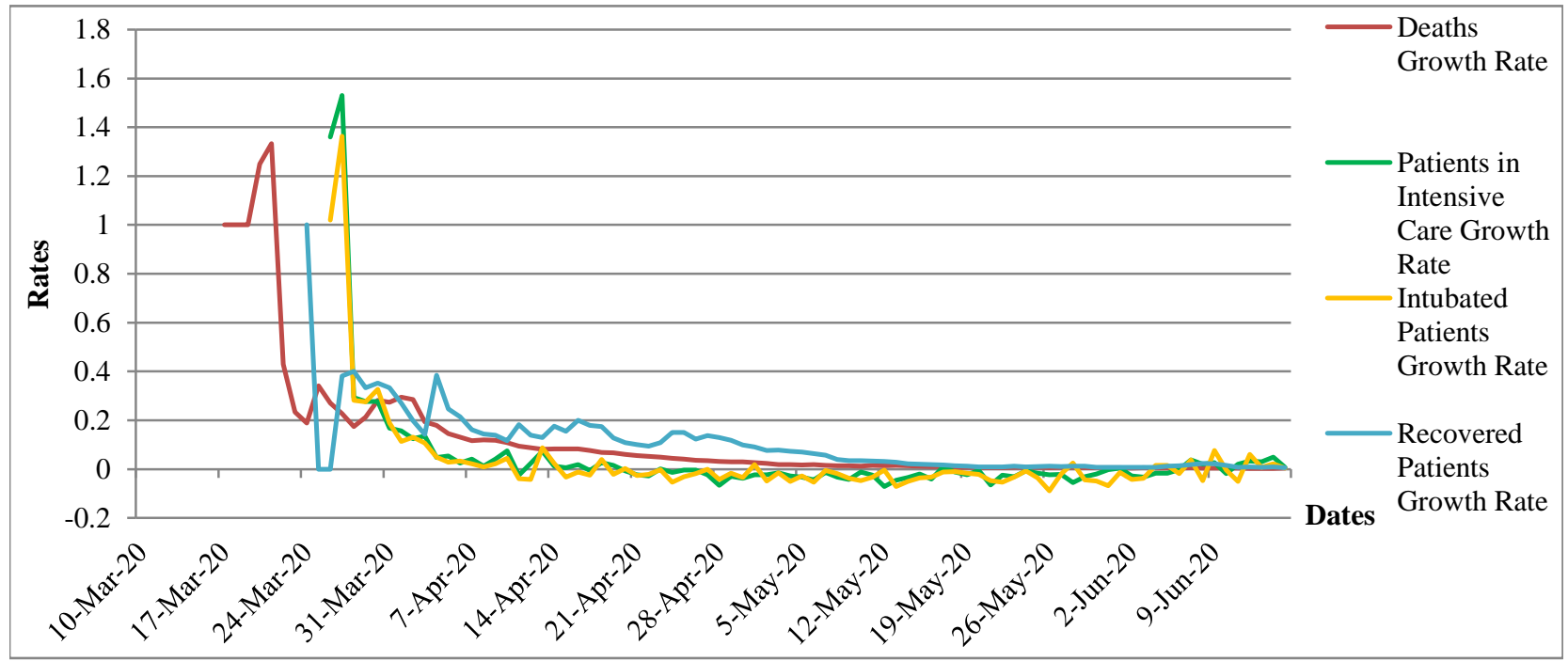

Figure 4: Growth Rates in Turkey (19) 


\section{Material and Methods}

The data used is from 10 March 2020 (the first day of the disease in Turkey) to 15 June 2020. This data is disclosed on a daily basis by the Ministry of Health of the Republic of Turkey (19). This data doesn't require any ethics committee report as it is publicly published by the Ministry of Health of the Republic of Turkey.

Statistical Analysis: In the study, firstly, a correlation matrix was applied. Afterward, the most suitable models were selected with the expert modeler method to forecast cases and deaths. The most proper models for both estimates were determined as ARIMA models. The analyzes and tests realized in this section were carried out on the IBM SPSS Statistics 20 program. Finally, the stationarity of the models found was examined by using the ADF test in EViews 9 program.

A correlation matrix describes the relationship among $\mathrm{m}$ variables, where the cross elements are equal to the merger. The square obtained from the variance-covariance matrix is a symmetrical, mxm-sized matrix. Both of these matrices include similar information, but the correlation matrix performs it is easier to relate variables (20). In the correlation matrix, the cross values are always 1.00 (100\%) since they are between the same variables. A p-value of less than 0.05 is statistically significant.

The autoregressive integrated moving average (ARIMA) models are widely utilization to model financial time series data. These models can be defined as:

$\varphi(B) y_{t}=\theta(B) a_{t}$

$\varphi(B)=1-\varphi_{1} B-\cdots-\varphi_{p} B^{p}$,

$\theta(B)=1-\theta_{1} B-\cdots-\theta_{q} B^{q}, B^{k} y_{t}=y_{t-1}$

where " $\mathrm{y}_{-} \mathrm{t}$ " is the financial time series, " $\mathrm{a}_{\mathrm{t}}$ " is a sequence of independent and identically distributed $\mathrm{N}(0, \sigma 2)$ random variables. The " $y_{t} s$ " can, in general, represent the difference or some other proper transformation of a nonstationary series " $\mathrm{x}_{\mathrm{t}}$ ". An appropriate portmanteau test of the hypothesis of model sufficiency is given by the BoxPierce (BP) test or another genre called the Ljung-Box (LB) test $(21,22)$. These test statistics comply with a chi-square distribution asymptotically if the model assumptions are true. Simulations performed for minor sample sizes have shown (22) that the LB test performs preferably than the $\mathrm{BP}$ test (23). Tests for residual autocorrelation are important tools for this task. A well-known instance is the LB test for residual autocorrelation. If the residuals are correlated, then the model should be reformed. Else, the residuals are white noise and the model is adequate to represent the time series (24). While the class of ARIMA models include a wide variety of time series, it does not compass time series that display repetitive behavior or periodic patterns. This recurrent nature is the essence of seasonal time series (25).

In the previous sections of this research, the spread of COVID-19 disease in other countries has been examined and general statistical information has been given about the 10 countries where this disease is seen the most. In the results section, estimates to future on the number of cases and deaths will be performed to determine the course of COVID-19 disease in Turkey.

One of the common methods to find the integration order of variables is unit root tests. One of the most popular among these tests is the ADF test. The ADF test is a Dickey-Fuller (DF) test with additional delays added to the dependent variables to eliminate the autocorrelation problem found in the time series. (26). The $\operatorname{ADF}$ test $(27,28)$ requires regressing the 1st difference of a variable $\mathrm{y}$ on its lagged level, exogenous variable(s) and $\mathrm{k}$ lagged first differences:

$\Delta Y_{t}=a+\beta T+p Y_{t-1}+\sum_{i=1}^{k} \gamma_{i} \Delta Y_{t-i}+e_{t}$

where "et" is an error term disturbance with mean zero and variance, "Yt" the variable in period $t$, " $\mathrm{T}$ " indicates a timetrend, " $\square$ " is the difference operator, and " $k$ " symbolizes the number of lags of the differences in the ADF equation. The ADF test is limited by its number of lags. It reduces the power of the test to reject the null of a unit root because the raised number of lags necessitates the estimation of extra parameters and a loss of a degree of freedom (29).

The JB test examining the normal distribution assumption was applied. One of the most famed tests for normality of regression residuals is the $\mathrm{JB}$ test (30), which has gained great acceptance among econometricians. The test statistic $\mathrm{JB}$ is a function of the measures of skewness (S) and kurtosis $(\mathrm{K})$ computed from the sample. Under normal distribution, the theoretical values of $\mathrm{S}$ and $\mathrm{K}$ are 0 and 3 , respectively (31). The test statistic JB is defined by

$J B=\frac{n}{6} \cdot\left(S^{2}+\frac{(K-3)^{2}}{4}\right)$

where $S=\hat{\mu}_{3} / \hat{\mu}_{2}^{3 / 2}$ is an estimator of $\beta_{1}=\mu_{3} / \mu_{2}^{3 / 2}$ and $K=\hat{\mu}_{4} / \hat{\mu}_{2}^{2}$ an estimator of $\beta_{2}=\mu_{4} / \mu_{2}^{2}$, and $\mu_{2}$ and $\mu_{3}$ are the theoretical second, $3^{\text {rd }}$ and $4^{\text {th }}$ central moments, respectively, with its estimates

$\hat{\mu}_{j}=\frac{1}{n} \sum_{i=1}^{n}\left(x_{i}-\bar{x}\right)^{j}, j=2,3,4$

The null hypothesis has to be rejected at 0.05 level if $J B \geq \chi_{0.05,2}^{2}(31)$

\section{Results}

\section{Correlation Matrix for COVID-19 in Turkey}

A correlation matrix suitable for the above information is given in Table 3. COVID-19 disease in Turkey due to cases, deaths, patients in ICU, intubated patients and the number of tests performed has been investigated on this matrix. Most of the relationship values (Spearman correlation) given in Table 3 are greater than $92 \%$ and significant as statistically, which indicates an elevated correlation between variables. For instance, the relationship value between cases and deaths is 0.997 . According to this correlation value, the deaths and cases up to 15 June affect each other by $99.7 \%$.

Except for the three $\mathrm{p}$-values $(\mathrm{p}>0.05)$ in Table 3 , the $\mathrm{p}$ values of all correlation values are statistically significant $(\mathrm{p}<0.05)$. 


\section{Forecasting Cases in Turkey with The ARIMA Model}

In this analysis, the $\operatorname{ARIMA}(0,2,4)$ model was utilized to estimate the future values of COVID-19 deaths in Turkey. In this type $(0,2,4)$ of the ARIMA model, the moving average (MA) is selected as 4 by taking the difference of the variables from the 2 nd degree. Since the $\mathrm{p}$-value is statistically significant ( $>>0.05)$, the H1a hypothesis is accepted (Table 4). The test statistic of the $\operatorname{ARIMA}(0,2,4)$ model shows that the defined model is appropriate for the time-series data (Ljung-Box Q Statistics $=20.423, \mathrm{DF}=16$, $p$-value $=0.202$ ) in Table 4. This implies that residuals from the model are white noise or independence.

H1a: The data are random and residuals aren't correlated. H1b: The data aren't random and residuals are correlated.
The parameters of the $\operatorname{ARIMA}(0,2,4)$ model (estimate, standard error (SE), t-statistics, and p-value) are given in Table 5. According to this table, the $\mathrm{H} 2$ a hypothesis is rejected, inasmuch as the $\mathrm{p}$-values for moving averages (lag 3 and lag 4$)$ are statistically significant $(\mathrm{p}<0.05)$. Thus, the $\operatorname{ARIMA}(0,2,4)$ model is determined to be statistically significant.

H2a: The ARIMA model is not statistically significant. H2b: The ARIMA model is statistically significant.

COVID-19 cases in Turkey were modeled as shown in Figure 3. In this figure, the date of 10 March 2020 was taken as the first day of COVID-19, and the forecast was made until 6 August 2020, the 150th day of the disease in Turkey. As a result of this forecast, it is estimated that there may be 266692 cases in Turkey on 6 August 2020. In other words, as of June 15, the total number of cases was estimated to increase by $48.30 \%$ after 52 days

Table 3: Correlation Matrix for COVID-19 Observations in Turkey

\begin{tabular}{|c|c|c|c|c|c|c|c|}
\hline & & Cases & Deaths & $\begin{array}{l}\text { Patients } \\
\text { in ICU }\end{array}$ & $\begin{array}{l}\text { Intubated } \\
\text { Patients }\end{array}$ & $\begin{array}{l}\text { Recovered } \\
\text { Patients }\end{array}$ & Tests \\
\hline Cases & $\begin{array}{l}\text { Spearman Correlation } \\
\text { p-value }\end{array}$ & 1 & $\begin{array}{r}0.999^{* *} \\
0.001\end{array}$ & $\begin{array}{l}-0.162 \\
0.127\end{array}$ & $\begin{array}{c}-0.275^{* * 3} \\
0.008\end{array}$ & $\begin{array}{c}0.999^{* 3 *} \\
0.001\end{array}$ & 1 \\
\hline Deaths & $\begin{array}{l}\text { Spearman Correlation } \\
\text { p-value }\end{array}$ & $\begin{array}{c}0.999^{* *} \\
0.001\end{array}$ & 1 & $\begin{array}{l}0.183^{*} \\
0.036\end{array}$ & $\begin{array}{c}-0.275^{* *} \\
0.008\end{array}$ & $\begin{array}{l}0.999^{* *} \\
0.001\end{array}$ & $\begin{array}{l}0.999^{* *} \\
0.001\end{array}$ \\
\hline $\begin{array}{l}\text { Patients in } \\
\text { ICU }\end{array}$ & $\begin{array}{l}\text { Spearman Correlation } \\
\text { p-value }\end{array}$ & $\begin{array}{c}-0.162 \\
0.127\end{array}$ & $\begin{array}{c}-0.162 \\
0.127\end{array}$ & 1 & $\begin{array}{l}0.968^{* *} \\
0.001\end{array}$ & $\begin{array}{l}-0.162 \\
0.1268\end{array}$ & $\begin{array}{c}-0.162 \\
0.127\end{array}$ \\
\hline $\begin{array}{l}\text { Intubated } \\
\text { Patients }\end{array}$ & $\begin{array}{l}\text { Spearman Correlation } \\
\text { p-value }\end{array}$ & $\begin{array}{c}-0.275^{* *} \\
0.008\end{array}$ & $\begin{array}{c}-0.275^{* *} \\
0.008\end{array}$ & $\begin{array}{l}0.968^{* * *} \\
0.001\end{array}$ & 1 & $\begin{array}{c}-0.275^{* *} \\
0.008\end{array}$ & $\begin{array}{c}0.275^{* *} \\
0.008\end{array}$ \\
\hline $\begin{array}{l}\text { Recovered } \\
\text { Patients }\end{array}$ & $\begin{array}{l}\text { Spearman Correlation } \\
\text { p-value }\end{array}$ & $\begin{array}{c}0.999^{* *} \\
0.001\end{array}$ & $\begin{array}{c}0.999^{* *} \\
0.001\end{array}$ & $\begin{array}{l}-0.162 \\
0.126\end{array}$ & $\begin{array}{c}-0.275^{* *} \\
0.008\end{array}$ & 1 & $\begin{array}{l}0.999^{* *} \\
0.001\end{array}$ \\
\hline Tests & $\begin{array}{l}\text { Spearman Correlation } \\
\text { p-value }\end{array}$ & 1 & $\begin{array}{c}0.999^{* *} \\
0.001\end{array}$ & $\begin{array}{l}-0.162 \\
0.127\end{array}$ & $\begin{array}{c}-0.275^{* *} \\
0.008\end{array}$ & $\begin{array}{l}0.999^{* * *} \\
0.001\end{array}$ & 1 \\
\hline
\end{tabular}

Table 4: Diagnostics of the $\operatorname{ARIMA}(0,2,4)$

\begin{tabular}{|c|c|c|c|c|c|c|c|c|c|}
\hline \multirow[t]{2}{*}{ Model } & \multirow{2}{*}{$\begin{array}{c}\text { Number } \\
\text { of } \\
\text { Predictors }\end{array}$} & \multicolumn{4}{|c|}{ Model Fit Statistics } & \multicolumn{3}{|c|}{ Ljung-Box Q(18) } & \multirow{2}{*}{$\begin{array}{c}\text { Number } \\
\text { of } \\
\text { Outliers }\end{array}$} \\
\hline & & $\mathbf{R}$ & RMSE & MAE & & & DF & & \\
\hline del_1 & 0 & 1.000 & 324.751 & 202.797 & 4.165 & 20.423 & 16 & 0.202 & 0 \\
\hline
\end{tabular}

Table 5: The ARIMA( $0,2,4)$ Model Parameters

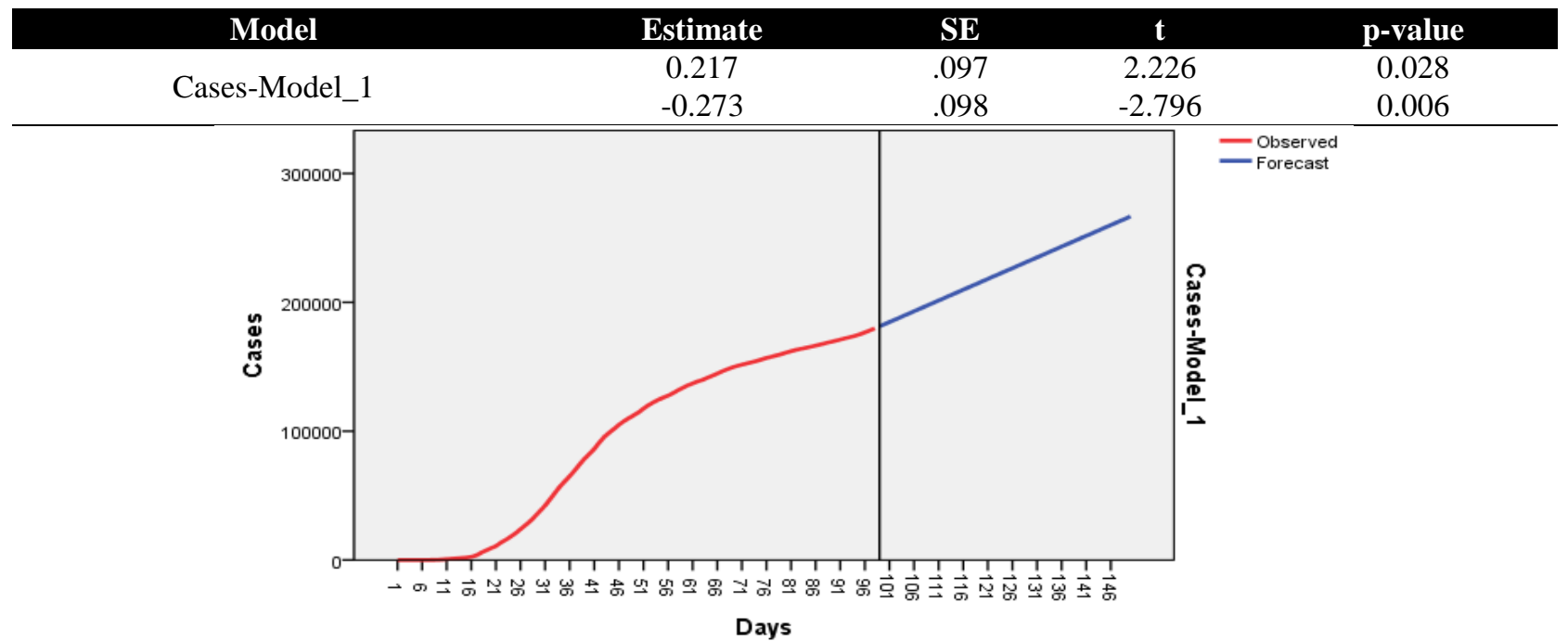

Figure 7: Forecasting Cases on the Curve 


\section{Forecasting Deaths in Turkey with The ARIMA Model}

In this analysis, the $\operatorname{ARIMA}(0,3,1)$ model was utilized to estimate the future values of COVID-19 deaths in Turkey. In this type $(0,3,1)$ of the ARIMA model, the MA is selected as 1 by taking the difference of the variables from the 3rd degree. Since the p-value is statistically significant ( $>0.05$ ), the H3a hypothesis is accepted (Table 6). The test statistic of the ARIMA $(0,3,1)$ model shows that the defined model is appropriate for the time-series data (Ljung-Box Q Statistics $=17.735, \mathrm{DF}=19, \mathrm{p}$-value $=0.406)$ in Table 6 .

H3a: The data are random and residuals aren't correlated. H3b: The data aren't random and residuals are correlated.

The parameters of the $\operatorname{ARIMA}(0,3,1)$ model are given in Table 7. According to this table, the H4a hypothesis is rejected, since the p-value for moving average (lag 1) is statistically significant $(\mathrm{p}<0.05)$. Thus, the $\operatorname{ARIMA}(0,3,1)$ model is determined to be statistically significant.

H4a: The ARIMA model is not statistically significant. H4b: The ARIMA model is statistically significant.

COVID-19 deaths growth rates in Turkey were modeled as shown in Figure 4. In this figure, the date of 10 March 2020 was taken as the first day of COVID-19, and the forecast was made until 6 August 2020, the 150th day of the disease in Turkey. As a result of this forecast, it is estimated that there may be 5718 deaths in Turkey on 6 August. In other words, as of June 15, the total number of deaths was estimated to increase by $18.50 \%$ after 52 days.

\section{The ADF Test for ARIMA Models}

The ARIMA $(0,2,4)$ model used for case estimation and the $\operatorname{ARIMA}(0,3,1)$ model used for death estimation are timeseries. For this reason, the stationarities of the observations in the models were examined. According to the results in Table 8 , p-values of both models are rejected by the H5a hypothesis $(\mathrm{p}<0.05)$.
Thus, for "Cases-Model_1" using the $\operatorname{ARIMA}(0,2,4)$, the stability of the model has been provided in the 2nd degree. Likewise, for "Deaths-Model_1" using the $\operatorname{ARIMA}(0,3,1)$, the stability of the model was provided in the 3rd degree. The use of the $\operatorname{ARIMA}(0,2,4)$ and $\operatorname{ARIMA}(0,3,1)$ models are statistically suitable.

H5a: The ARIMA model is non-stationary and has a unit root.

H5b: The ARIMA model is stationary and hasn't a unit root.

\section{The ACF and PACF Plots of Cases and Deaths}

The ACF and PACF plots of the used time series should be given to see the non-stationary in the data graphically. ACF and PACF graphs are time series graphs used for stationarity testing. Firstly, ACF and PACF graphs are given for non-difference of cases series and the 2nd difference of cases series (Figure 9). When the 2nd difference of the cases is taken, it is seen that they are stationary.

Subsequently, ACF and PACF graphs are given for nondifference of deaths series and the 3rd difference of deaths series (Figure 10). When the 3rd difference of the cases is taken, it is seen that they are stationary. Thus, the state of stationary was also evaluated on the graphs.

\section{The Normality of the Errors}

Cases and deaths used in ARIMA models should provide the normality assumption. For this purpose, the JB test was used to find out whether the errors are suitable for normal distribution. According to the JB test results given in Table 9, p-values for both cases and deaths are greater than 0.05 ( $>0.05)$. Thus, the H6a hypothesis cannot be rejected. Both cases and deaths are suitable for normal distribution.

H6a: Errors show a spread suitable for normal distribution. H6b: Errors don't show a spread suitable for normal distribution.

Table 6: Diagnostics of the ARIMA(0,3,1)

\begin{tabular}{cccccccccc} 
Model & Number of & \multicolumn{3}{c}{ Model Fit Statistics } & \multicolumn{3}{c|}{ Ljung-Box Q(18) } & Number \\
& Predictors & R-squared & RMSE & MAE & MAPE & Statistics & DF & $\begin{array}{c}\text { p- } \\
\text { value }\end{array}$ & Outliers \\
\hline $\begin{array}{c}\text { Deaths- } \\
\text { Model_1 }\end{array}$ & 0 & 1.000 & 5.449 & 4.053 & 2.984 & 17.735 & 17 & 0.406 & 0 \\
\hline
\end{tabular}

Table 7: The ARIMA(0,3,1) Model Parameters

\begin{tabular}{lcccc} 
Model & Estimate & SE & t & p-value \\
Deaths-Model_1 & 0.835 & 0.059 & 14.225 & 0.001 \\
\hline
\end{tabular}




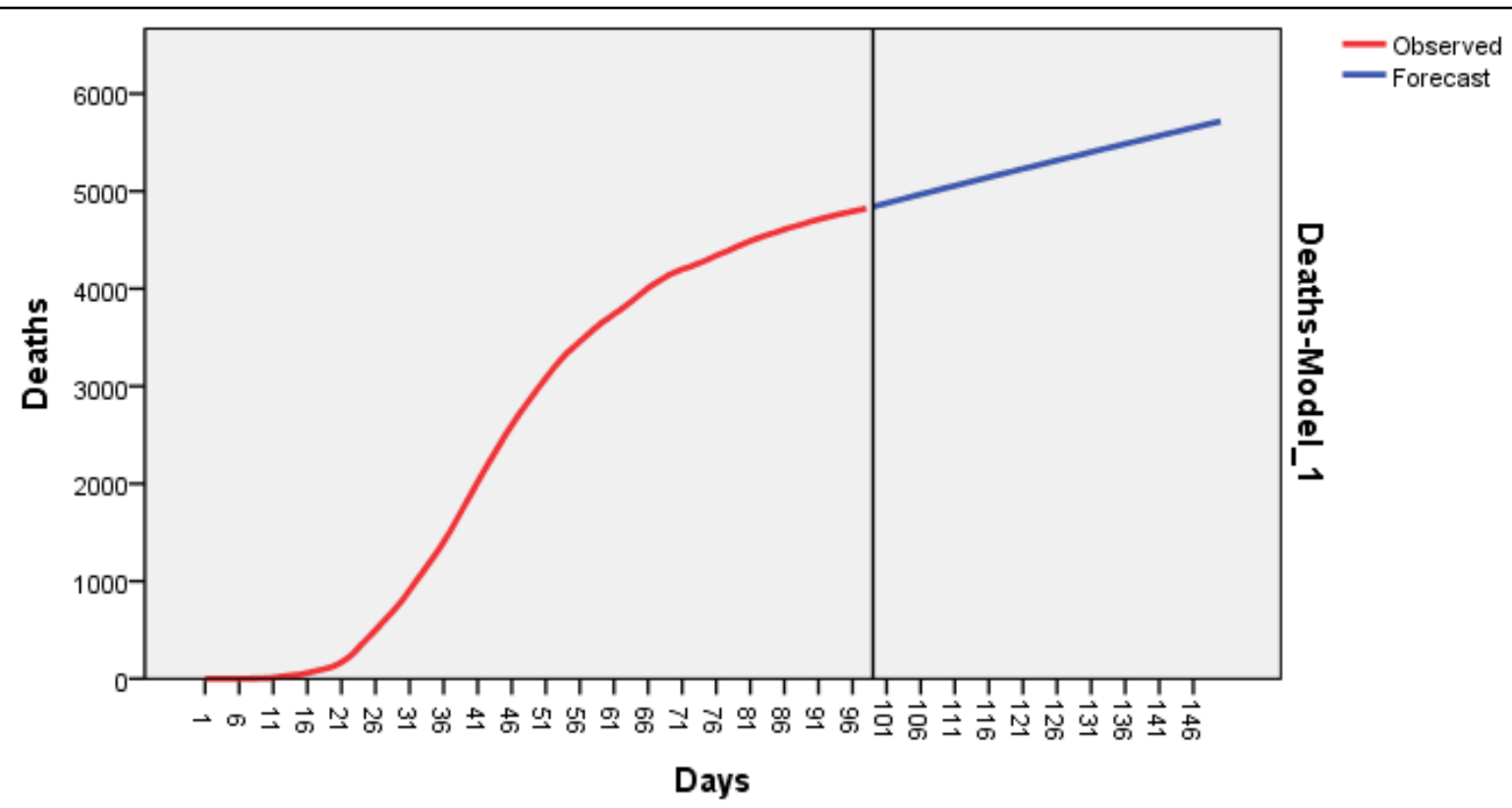

Figure 8: Forecasting Deaths on the Curve

Table 8: The ADF Test

\begin{tabular}{ccccc} 
Models & \multicolumn{2}{c}{ Non-Differences } & \multicolumn{2}{c}{ Current Differences } \\
& t-Statistics & p-value & t-Statistics & p-value \\
\hline Cases-Model_1 & -0.280 & 0.5824 & $-3.822^{*}$ & $0.0002^{*}$ \\
Deaths-Model_1 & -0.676 & 0.4217 & $-17.844 * *$ & $0.0001 * *$ \\
\hline
\end{tabular}

Note: *the difference of the observations from the $2^{\text {nd }}$ degree was taken.

Note 2: **the difference of the observations from the $3^{\text {rd }}$ degree was taken

\begin{tabular}{|c|c|c|c|c|c|}
\hline \multicolumn{2}{|c|}{ Autocorrelation } & \multicolumn{2}{|c|}{ Partial Correlation } & Autocorrelation & Partial Correlation \\
\hline 1 & \begin{tabular}{|l} 
\\
\end{tabular} & 1 & & 101 & 101 \\
\hline 1 & & 10 & 1 & 다. & $\square 1$ \\
\hline 1 & 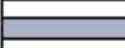 & 10 & 1 & 1다 & 1니 \\
\hline 1 & 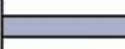 & 10 & 1 & $1 \square$ & $1 \longmapsto$ \\
\hline 1 & ए & 10 & 1 & $1 \longdiv { \square }$ & $1 \longdiv { 7 1 }$ \\
\hline 1 & 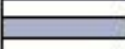 & 10 & 1 & 10 & $1 \sqrt{1}$ \\
\hline 1 & 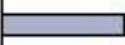 & 10 & 1 & $1]$ & । \\
\hline 1 & $\square$ & 10 & 1 & $1 曰$ & 15 \\
\hline 1 & $\square$ & 10 & 1 & । & 吅 \\
\hline 1 & 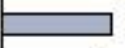 & 10 & 1 & $1 \longdiv { 1 }$ & $1 \longdiv { 7 }$ \\
\hline 1 & \begin{tabular}{|l} 
\\
\end{tabular} & 10 & 1 & 101 & 11 \\
\hline 1 & $\square$ & 10 & 1 & 11 & 101 \\
\hline 1 & $\square$ & 10 & 1 & 18 & 11 \\
\hline 1 & 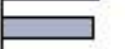 & 10 & 1 & 1 & 101 \\
\hline 1 & $\square$ & 10 & 1 & 11 & 11 \\
\hline 1 & $\square$ & 10 & 1 & ו & ון \\
\hline
\end{tabular}

Figure 9: The ACF and PACF Plots of Cases 
these predicted values do not include possibilities such as

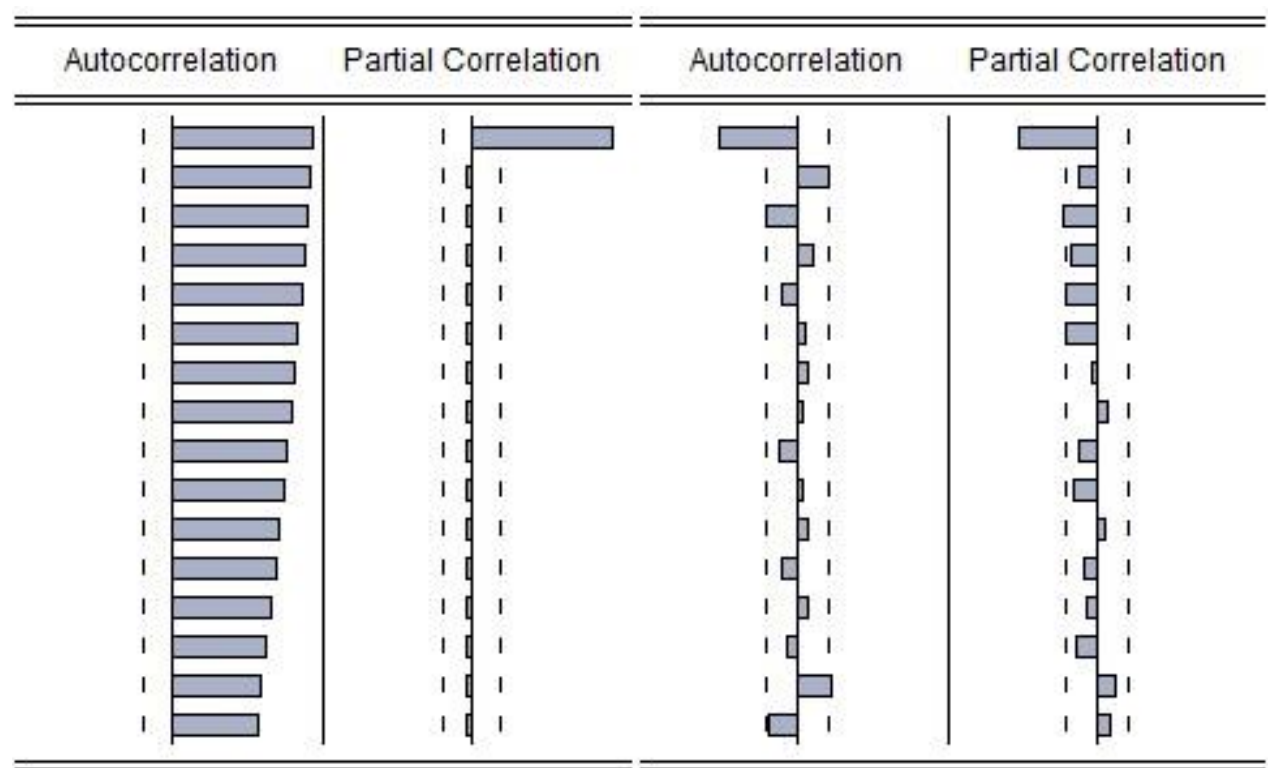

Figure 10: The ACF and PACF Plots of Deaths

Table 9: The JB Test

\begin{tabular}{lll} 
Statistics & Cases & Deaths \\
Mean & 22.135 & 0.073 \\
Median & 4.000 & 0.000 \\
Maximum & 877.000 & 17.000 \\
Minimum & -778.000 & -16.000 \\
Skewness & 0.382 & -0.089 \\
Kurtosis & 3.945 & 2.929 \\
Jarque-Bera & 5.918 & 0.147 \\
p-value & 0.051 & 0.928 \\
\hline
\end{tabular}

\section{Discussion}

As of June 15, the SARS-CoV-2 virus has caused 8066465 infected people and 437295 deaths in the world. The disease caused by this virus is called COVID-19, and this disease has become a big epidemic over time. The fact that there is currently no definitive treatment and vaccine makes this disease more dangerous. Germany, which is one of the 10 countries where the disease is most common, is $1 \mathrm{st}$ country with the highest rate with $91.82 \%$ recovery rate, while the United Kingdom, which is another one of the 10 countries where the disease is most common, is the last country with $0.43 \%$ recovery rate. The U.S.A., Spain, and Peru, which are among the top 10 countries, are the countries with the highest number of cases when compared with their population. Likewise, Spain, Italy, and the U.K. are the countries with the highest number of deaths when compared with their population. Certainly, the fact that the elderly population in Europe is higher than other regions is one of the reasons for the high death rates.

In both the models established to predict the COVID-19 cases and COVID-19 deaths, it has been estimated that the disease may not end yet and deaths may continue. If the disease progresses in its current stable course, observations close to the predicted results may be obtained. Because
SARS-CoV-2 virus undergoing a fatal mutation. COVID19 has a certain lethality rate, which is an average of $5.42 \%$ for the world. When this lethality rate was taken into consideration, it was observed that the estimate of death in Turkey (\%2.14) was consistent and lower than the world.

The main aim of this study was to examine COVID-19 cases and deaths in Turkey and to predict their future state. At this point, Turkey, despite being one of the countries where COVID-19 cases last seen, has been one of the countries where the disease is most prevalent. On the 97th day of the disease, a total of 179831 cases and 4825 deaths estimated in Turkey. 152364 people of these cases were recovered, and the recovery rate was found as $84.73 \%$. The death rate was found to be $2.68 \%$, which is below the world's deaths average of 5.42\%. By 15 June, 2674203 COVID-19 tests were performed. The average growth rates were found as follows: cases $18.35 \%$, deaths $12.66 \%$, patients in ICU $4.64 \%$, intubated patients $3.38 \%$, and recovered patients $10.36 \%$.

Consequently of the analysis and models established for forecast, the following results were found: Approximately 266692 COVID-19 cases and 5718 COVID-19 deaths may 
occur in Turkey on the 150th day of the disease. For these alarming and increasing estimation values, Turkey must be careful and rigorously manage the process.

Thus, this hardly process, which may pass until a vaccine and an effective treatment are found, can be overcome with minimal loss.

\section{Conclusion}

Consequently of the analysis and models established for forecast, the following results were found: Approximately 266692 COVID-19 cases and 5718 COVID-19 deaths may occur in Turkey on the 150th day of the disease. For these alarming and increasing estimation values, Turkey must be careful and rigorously manage the process. Thus, this hardly process, which may pass until a vaccine and an effective treatment are found, can be overcome with minimal loss

\section{Acknowledgement, Funding: None.}

Author's contributions: YAÜ, OD; Study design, Data Collection and analyses OD; Article preparation and revisions

Conflict of interest: The authors declare that they have no conflict of interest. The study was authorized by the Harran University Medical Faculty local ethics committee

\section{References}

1. Suzanne AA. A pest in the land: new world epidemics in a global perspective. Kindle ed. New Mexico: University of New Mexico Press; 2003.

2. Henderson D. Smallpox: the death of a disease. 1st ed. Amherst, NY: Prometheus Book; 2009.

3. Spreeuwenberg P, Kroneman M, Paget J. Reassessing the global mortality burden of the 1918 influenza pandemic. American Journal of Epidemiology. 2018;187(12):2561-7.

4. who.int [Internet]. Geneva: Naming the coronavirus disease (COVID-19) and the virus that causes it; c2020 [cited 2020 Mar 31]. Available from: https://www.who.int/emergencies/diseases/novelcoronavirus-2019/technical-guidance/naming-the-coronavirusdisease-(covid-2019)-and-the-virus-that-causes-it.

5. ictvonline.org [Internet]. Berlin: International Committee on Taxonomy of Viruses (ICTV); c2020 [cited 2020 Mar 31]. Available from: https://talk.ictvonline.org/.

6. Ren LL, Wang YM, Wu ZQ, Xiang ZC, Guo L, Xu T, et al. Identification of a novel coronavirus causing severe pneumonia in human: a descriptive study. Chinese Medical Journal. 2020;133(9):1015-24.

7. Fauci AS, Lane HC, Redfield RR. Covid-19 - navigating the uncharted 2020. The New England Journal of Medicine. 2020;382(13):1268-9.

8. cdc.gov [Internet]. Atlanta: Centers for Disease Control and Prevention. Symptoms of Coronavirus; c2019 [cited 2020 Mar 31]. Available from: https://www.cdc.gov/coronavirus/2019ncov/symptoms-testing/symptoms.html.

9. who.int [Internet]. Geneva: Laboratory testing for 2019 novel coronavirus (2019-nCoV) in suspected human cases; c2020 [cited 2020 Mar 31]. Available from: https://www.who.int/publicationsdetail/laboratory-testing-for-2019-novel-coronavirus-in-suspectedhuman-cases-20200117.
10. Hao Q, Wu H, Wang Q. Difficulties in false negative diagnosis of coronavirus disease 2019: a case report. North Carolina: Research Square; 2020.

11. Cascella M, Rajnik M, Cuomo A, Dulebohn SC, Napoli RD Features, evaluation and treatment coronavirus (COVID-19). Treasure Island (FL): StatPearls Publishing; 2020. https://www.ncbi.nlm.nih.gov/books/NBK554776/.

12. Wang M, Cao R, Zhang L, Yang X, Liu J, Xu M, et al. Remdesivir and chloroquine effectively inhibit the recently emerged novel coronavirus (2019-nCoV) in vitro. Cell Research. 2020;30:269-71

13. Savarino A, Boelaert JR, Cassone A, Majori G, Cauda R. Effects of chloroquine on viral infections: an old drug against today's diseases? The Lancet Infectious Diseases. 2003;3(11):722-7.

14. Yan Y, Zou Z, Sun Y, Li X, Xu KF, Wei Y, et al. Anti-malaria drug chloroquine is highly effective in treating avian influenza a H5N1 virus infection in an animal model. Cell Research. 2013;23(2):300-2

15. Gao J, Tian Z, Yang X. Breakthrough: chloroquine phosphate has shown apparent efficacy in treatment of COVID-19 associated pneumonia in clinical studies. BioScience Trends Advance Publication. 2020;14(1):72-3.

16. who.int [Internet]. Geneva: WHO R\&D blueprint: informal consultation on prioritiza-tion of candidate therapeutic agents for use in novel coronavirus 2019 infection; c2020 [cited 2020 Apr 1]. Available from: https://apps.who.int/iris/bitstream/handle/10665/330680/WHOHEO-RDBlueprint $\% 28 \mathrm{nCoV} \% 29$-2020.1-eng.pdf

17. gisanddata.maps.arcgis.com [Internet]. Maryland: Coronavirus COVID-19 global cases by the center for systems science and engineering (CSSE); c2020 [cited 2020 June 15]. Available from: https://gisanddata.maps.arcgis.com/apps/opsdashboard/index.html\#/b da7594740fd40299423467b48e9ecf6.

18. worldometers.info [Internet]. Shanghai: World Population; c2020 [cited 2020 Apr 6]. Available from: https://www.worldometers.info/world-population.

19. saglik.gov.tr [Internet]. Ankara: Republic of Turkey, Ministry of Health; c2020 [cited 2020 June 15]. Available from: https://covid19.saglik.gov.tr/.

20. Horn RA, Johnson CR. Matrix analysis. 1st ed. Cambridge: Cambridge University Press; 1985.

21. Box GEP, Pierce DA. Distribution of residual autocorrelations in autoregressive integrated moving average time series models. Journal of the American Statistical Association. 1970;65(332):150926.

22. Ljung GM, Box GEP. On a measure of lack of fit in time serie models. Biometrika. 1978; 65(2):297-303

23. Warriyar KV, Abraham B, Variyath AM. Robustness of some portmanteau correlation tests in financial time series. American Journal of Mathematical and Management Sciences. 2016;35(1):6776.

24. Bako H, Rusiman M, Ibrahim L, Hazel Monica M.-P. Predictive modeling of pelagic fish catch in malaysia using seasonal ARIMA models. Agriculture, Forestry and Fisheries. 2013;2(3):136-40.

25. Thomopoulos NT. Applied forecasting methods. 1st ed. New Jersey, Englewood Cliffs: Prentice-Hall; 1980.

26. Mushtaq R. Augmented dickey fuller test. SSRN Electronic Journal 2012;1-19.

27. Dickey DA, Fuller WA. Distribution of the estimators for autoregressive time series with a unit root. Journal of The American Statistical Association. 1979;74(366):427-31. 
28. Dickey DA, Fuller WA. Likelihood ratio statistics for autoregressive time series with a unit root. Econometrica: Journal of the Econometric Society. 1981;49(4):1057-72.

29. Hosseini SM, Ahmad Z, Lai YW. The role of macroeconomic variables on stock market index in china and india. International Journal of Economics and Finance. 2011;3(6):233-43.
30. Jarque CM, Bera AK. Efficient tests for normality, homoscedasticity and serial independence of regression residuals. Economics Letters. 1980;6:255-9.

31. Thadewald $\mathrm{T}$, Büning $\mathrm{H}$. Jarque-bera test and its competitors for testing normality - a power comparison. Journal of Applied Statistics. 2007;34(1):87-105.

Copyright (C) 2020 The Author(s); This is an open-access article distributed under the terms of the Creative Commons Attribution License (http://creativecommons.org/licenses/by/4.0), (CC BY NC) which permits unrestricted use, distribution, and reproduction in any medium, provided the original work is properly cited. International journal of Medical Science and Discovery. 